\title{
PowerPoint or chalk and talk: Perceptions of medical students versus dental students in a medical college in India
}

This article was published in the following Dove Press journal:

Advances in Medical Education and Practice

27 August 2010

Number of times this article has been viewed

\section{Vikas Seth \\ Prerna Upadhyaya \\ Mushtaq Ahmad \\ Vijay Moghe}

Department of Pharmacology, Mahatma Gandhi Medical College, Jaipur, Rajasthan, India
Correspondence: Vikas Seth Department of Pharmacology, Mahatma Gandhi Medical College, Sitapura, Jaipur - 302022, India

$\mathrm{Tel}+9 \mid 9983336746$

Fax +9| |4| 277 |359

Email drvseth@rediffmail.com
Purpose: To assess students' perceptions of the impact of PowerPoint (PPT) presentations in lectures in comparison to the traditional chalk and talk method and lectures using transparencies and overhead projector (TOHP). The study analyzes the preferences for teaching aids of medical students versus dental students.

Methods: Second year medical and dental undergraduates were asked to fill in a nine-item questionnaire about their perceptions of the three lecture delivery methods. Following analysis of the questionnaire the students were interviewed further. The results were analyzed separately for medical and dental students to see if there was any difference in their perceptions.

Results: The majority of the medical students (65.33\%) preferred PPT presentations, while $15.16 \%$ of students preferred the lectures using chalkboard, and $19.51 \%$ preferred TOHP for teaching $(P<0.001)$. Of the dental students: $41.84 \%$ preferred chalkboard, $31.21 \%$ preferred TOHP, and $25.85 \%$ students preferred PPT presentations in the lectures $(P<0.05)$. Some important comments of the students were also recorded on interview which could be valuable for the medical teachers.

Conclusion: The medical students clearly preferred the use of PPT presentations while the dental students did not. The study does not bring out evidence based superiority of any lecture delivery method. It appears that in the hands of a trained teacher any teaching aid would be appropriate and effective. This highlights the need for formal training in teaching technologies to develop good presentation skills and thus motivate the students.

Keywords: audiovisual aids, medical education, lecture delivery methods, PowerPoint presentations, OHP, chalkboard

\section{Introduction}

Lectures have been the most common form of teaching and learning since ancient times. ${ }^{1}$ Although discussion methods in small groups appear to be a superior method of attaining higher-level intellectual learning, ${ }^{2}$ in India it is almost inevitable that medical students will experience lectures, as the number of students attending medical schools is too large in comparison to the teaching staff available. Hence, the lecture is here to stay, so it is immensely important that it should be as effective as possible. ${ }^{3}$

During a lecture, both the visual and auditory senses are used to absorb information and here assistance in the form of a visual aid is useful. ${ }^{4} \mathrm{~A}$ chalkboard is uniquely effective as a medium of classroom instruction and has been used commonly in lectures, while the use of transparencies with an overhead projector (TOHP) is also popular. ${ }^{5}$ The once-popular 35-mm slide projector seems to be headed for extinction. Recently the use of electronic presentations has become common and Microsoft PowerPoint (PPT) 
is now the most popular package used out of all electronic presentations. ${ }^{6}$

PPT-based lectures are increasingly being delivered in medical colleges as in other colleges and universities. ${ }^{7}$ However, educationists are divided on the superiority of PPT with respect to the traditional chalk and talk method. ${ }^{8}$ Various studies have been conducted to assess the effectiveness of lectures using PPT or other such media in comparison to lectures using chalkboard, or the use of TOHP.

According to one study, traditional classes with blackboard presentation were the most favored by students from biomedicine and medicine courses ${ }^{9}$ while another study observed that most students preferred PPT presentations over traditional presentations (eg, chalk and talk). ${ }^{10}$ It has been suggested that the use of PPT can help teachers to 'help their students learn'. ${ }^{11}$ One study noted that students preferred PPT over the use of TOHP, but that in some instances the content of the PPT presentation distracted students. ${ }^{12}$ An extensive study comparing PPT and TOHP observed no difference in students' performance in tests ${ }^{13}$ while in another study there was marked improvement in examination results when PPT replaced the use of TOHP. ${ }^{14}$

Hence, there is a mixture of views based on the studies and it is not clear whether a particular lecture delivery method is superior to others. Moreover, most of these studies have been conducted in the developed countries and the area has not really been explored in the developing countries where factors like power disruptions are important considerations. Therefore, the present study was planned in a medical college in the state of Rajasthan, India, to assess the students' perceptions of the impact of PPT presentations in lectures compared with the traditional chalk and talk method, and lectures using TOHP. The study analyzes the preferences for teaching aids of medical students versus dental students.

\section{Materials and methods}

A questionnaire-based survey of the medical and dental undergraduate students in a private medical college in Jaipur, India was conducted after getting permission from the principal and institutional ethics committee of the college. In this college, the annual intakes of medical and dental students are 100 and 60 respectively. The questionnaire was circulated to all second-year medical and dental students. A total of 62 medical students (40 males and 22 females) and 44 dental students (13 males and 31 females) completed the questionnaire.

The students were asked to fill in the following structured questionnaire about their views and perception of three methods of lecture delivery, viz: PPT presentation, using a chalkboard, and TOHP. For each of the three methods, the students were asked to rank the following nine comments on a five-point scale: agree strongly, agree, no opinion, disagree, or disagree strongly.

1. The lectures were well organized

2. The lectures were well audible

3. The board work or audiovisual aids were clear

4. The lectures were clear and understandable

5. The lecture stimulated my interest

6. The lecture advanced my understanding

7. The lecture delivery was interesting

8. I was able to take my notes/diagrams

9. The lecture contents were well informative

The students were also interviewed further in the light of analysis of the questionnaire.

The above nine parameters were analyzed on the basis of scale of grading, ie, 2 (agree strongly), 1 (agree), 0 (no opinion), -1 (disagree) and -2 (disagree strongly). The sum of all the students' gradings on each parameter was used to calculate the final weighted score. The overall preference of the students is estimated using the method of weighted average, for finding the weighted score of each parameter regarding the different lecture delivery methods.

The results were analyzed separately for medical and dental students to see if there is any difference in their perceptions. Statistical analysis was done using one-way ANOVA.

\section{Results}

\section{Perceptions of medical students}

The majority of the second year medical students rated PPT-based teaching higher in terms of all the parameters studied as compared to the chalkboard or TOHP-based teaching. The medical students' opinions (as weighted scores) are represented in Figure 1.

The medical students' preferences for each teaching aid (given as a percentage) are as follows:
- PPT:
$65.33 \%$
- Chalkboard:
$15.16 \%$
- TOHP:
$19.51 \%$

The preference for PPT is significantly greater than for the other two teaching methods $(P<0.001)$.

\section{Perceptions of dental students}

Figure 2 presents the dental students' opinions (as weighted scores) of the lectures using different teaching aids. 


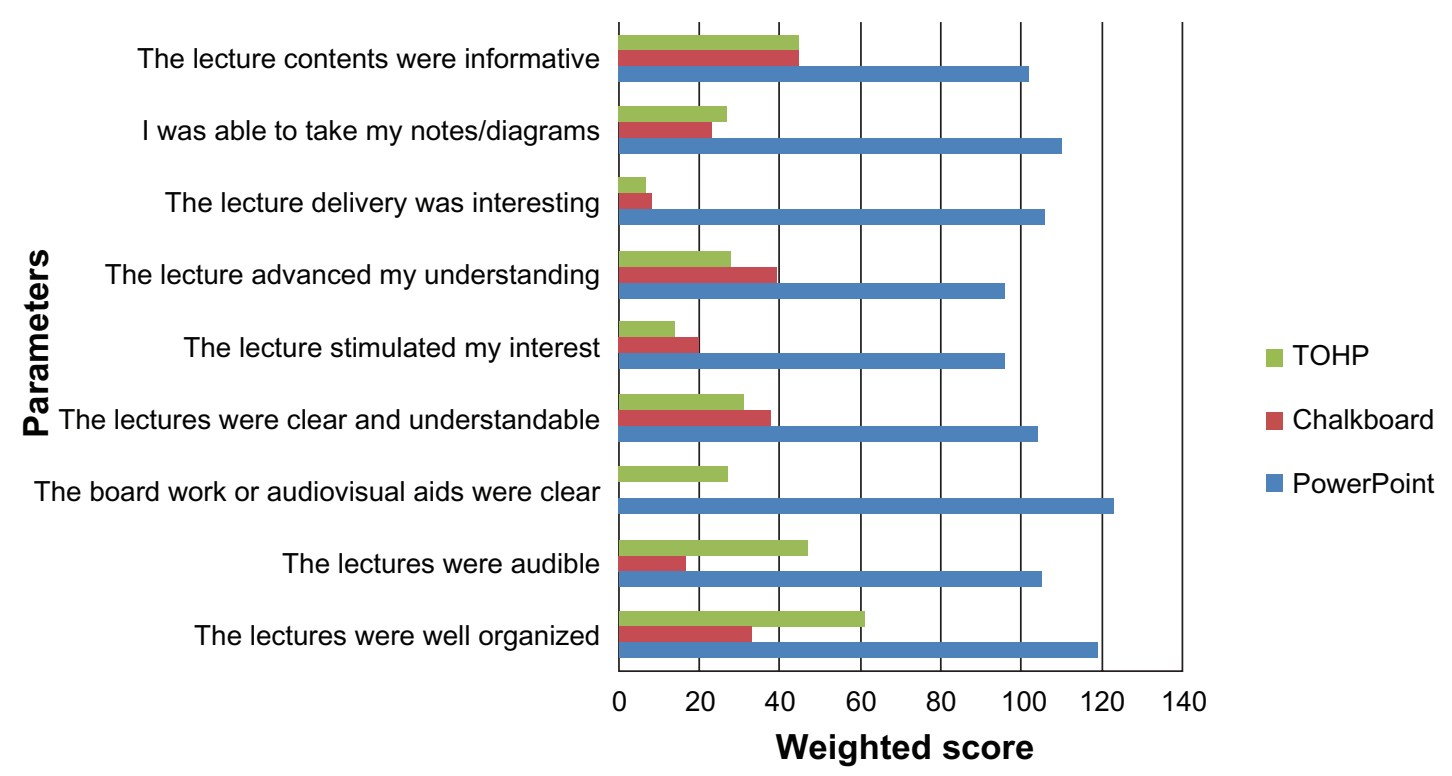

Figure I Medical students' opinions of the lectures using different teaching aids. Abbreviation: TOHP, transparencies and overhead projector.

The dental students' preferences for a teaching aid (given as a percentage) are as follows:

- PPT: $25.85 \%$

- Chalkboard: $\quad 41.84 \%$

- TOHP: $\quad 32.31 \%$

For dental students the difference in the preferences for the teaching aids is not statistically significant. $(P>0.05)$.

In the opinion of the majority of second year dental students:

1. With the chalk and talk method, the lectures are clear and understandable, interesting and interactive, they stimulate their interest and advance their understanding of the subject. Most importantly, the students are able to take down the notes and diagrams.

2. With PPT the lectures were well-organized.

3. With TOHP, the lectures were clearly audible and informative.

\section{Comparison of preferences: medical students versus dental students}

The medical students clearly preferred the use of PPT presentations $(65.33 \%)$ while the dental students did not prefer them

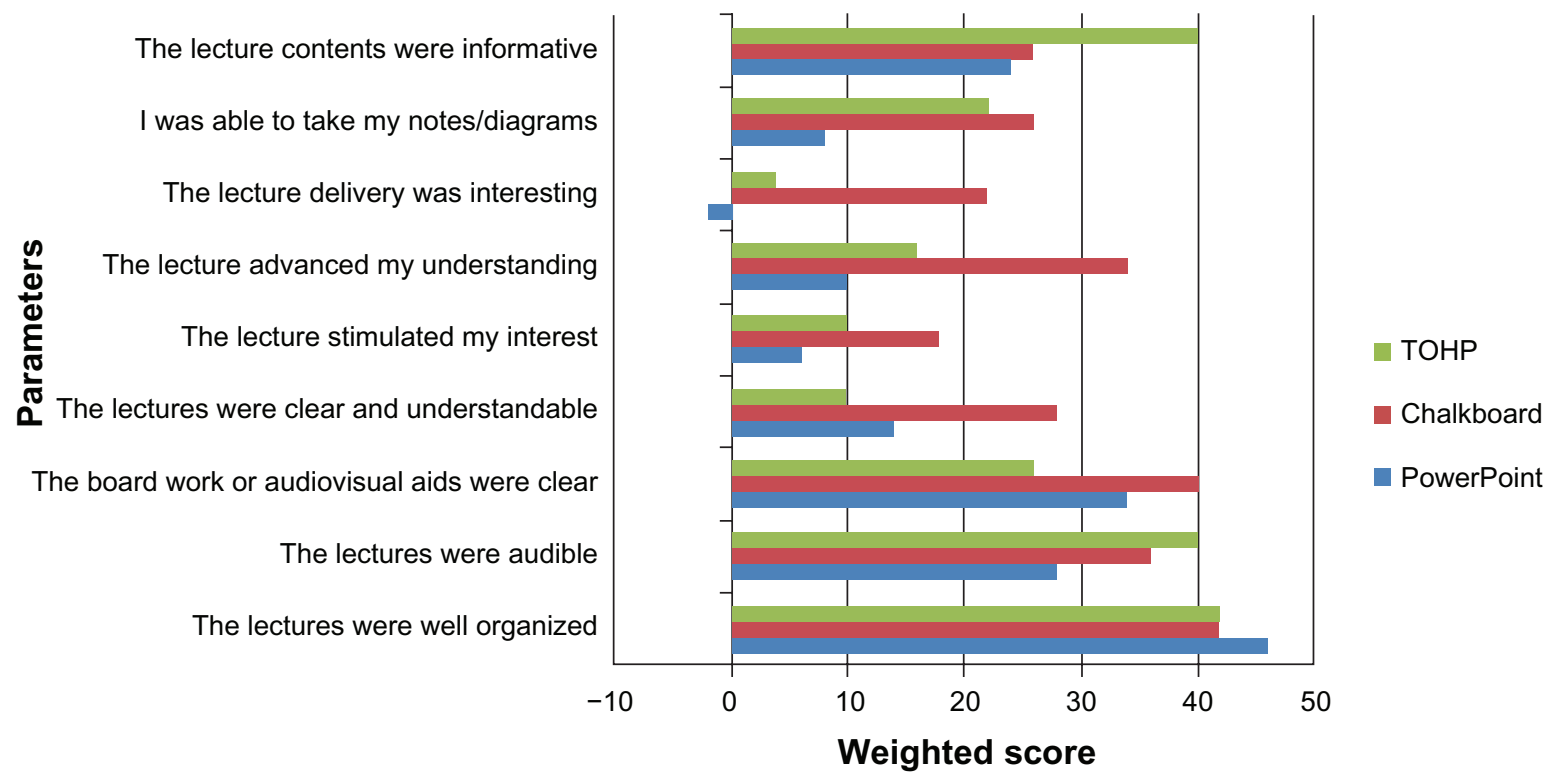

Figure 2 Dental students' opinions of the lectures using different teaching aids. Abbreviation: TOHP, transparencies and overhead projector. 
(25.85\%). The chalk and talk method was the most preferred method among the dental students (41.84\%) but this was not much appreciated by the medical students (15.16\%). The dental students showed more affinity towards the use of TOHP (32.31\%) as compared to their medical colleagues (19.51\%). Figure 3 compares the preferences of medical students versus dental students for each of the three teaching aids.

\section{Important comments given by the medical and dental students on interview \\ Chalkboard}

- The main reasons for liking this technique are that the student-teacher interaction is better, it encourages taking down the notes and diagrams as the students follow the hands of the teacher, and the lecture contains natural pauses and breaks. Power failure could not interrupt the lecture.

- The main reasons for disliking this technique are that poor handwriting is not legible and sometimes the blackboard is dirty, especially if used several times in the day, and at times the chalk is faulty and it soils the clothes. Also fewer diagrams can be provided and less information can be covered in the lecture.

\section{Transparencies and overhead projector}

- The main reasons for liking this technique are that more information on the topic can be covered in a shorter time and it avoids the issue of a dirty blackboard and faulty chalks.

- The main reason for disliking this technique is that any power failure interrupts the lecture, and sometimes the lecture delivery is too fast.

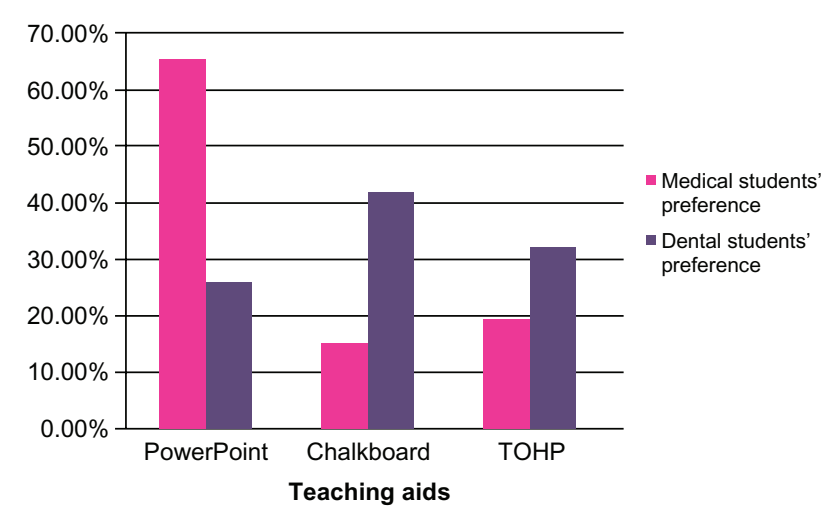

Figure 3 Comparison of preferences for the teaching aids: medical students versus dental students.

Abbreviation: TOHP, transparencies and overhead projector.
- Recommendation: TOHP should be used with the blackboard to elaborate some points.

- Often if a large amount of information is presented in a single transparency it makes the lecture monotonous and it is difficult to concentrate.

- The issue of poor visibility and poor handwriting can be avoided by printing eg, by using PPT printouts and photocopying on the transparencies. The letter size should be clearly legible from a distance.

\section{PowerPoint (PPT) presentation}

- The main reasons for liking this technique are that it provides a better quality of text and diagrams, and it avoids the issue of dirty blackboard and faulty chalks. PPT is more interesting because it can incorporate animations, pictures, graphs, 3D images, sequences of images, and videos.

- The main reasons for disliking this technique are that it needs the room to be darkened, it takes longer to set up the projection, and any power failure interrupts the lecture. Some teachers go too fast and then students find it difficult to take down the notes and diagrams.

- Judicious use of animations makes PPT more interesting and has a lasting impact.

- It is ideal for fast revision and quick overview of the subject and for seminars.

- PPT presentations should contain more diagrams and flow charts and less text.

- Points should appear line by line and each point should also be explained and not just skipped over.

- Sufficient time should be given for students to take down their notes and the diagrams.

\section{General comments}

- Regardless of the teaching aid used the impact of a lecture depends on the teacher.

- More examples, diagrams and flow charts make the lecture more easily understandable.

\section{Discussion}

This study clearly highlights the point that the preferences for the method of lecture delivery of students in different faculties can vary so much within the same institution. Regarding the preference of medical students, the order of priority of teaching aids was: PPT $>$ TOHP $>$ chalkboard. In the case of dental students, the order of their preference was: chalkboard $>$ TOHP $>$ PPT. The medical students significantly preferred the use of PPT while dental students did not prefer it. 


\section{Possible reasons for the difference in perception of medical and dental students}

The syllabus and curriculum of dental students are different from those of the medical students. Dental students have less detail in their medical subjects, but the dental students are taught their medical subjects by the same faculty which teaches the medical students.

So the most probable reason for the noted differences of opinion might be that when the medical teachers are teaching the dental students they don't reduce their PPT presentation material as per the specific needs of their dental students. This is confirmed in our students' interviews which showed that the dental students did not prefer PPT mainly because the PPT presentations contained too much material and the lectures were delivered too fast. PPT is a program which can make a lecture very interesting ${ }^{15}$ or can cause distraction; ${ }^{12}$ the difference is up to the teacher using it. ${ }^{16}$

Moreover, among the dental students there were more females $(70.45 \%)$ while among the medical students there were more males (64.5\%). Some studies have observed that male students are more positive in their perceptions on the use of technology in teaching. ${ }^{17}$ So it is possible that medical students, consisting predominantly of male students, perceive the use of PPT presentations more positively than the dental students, where there are more females.

Some previous studies have found that students preferred $\mathrm{PPT}^{10-12}$ while in others the students preferred traditional blackboard teaching to TOHP and PPT. ${ }^{9}$ One extensive study has suggested that the efficacy of PPT is case specific rather than universal. ${ }^{13}$

The majority of medical students prefer PPT presentations, mainly because PPT presentations avoid the issue of poor handwriting and dirty blackboards. The students found presentations more interesting, as noted earlier, perhaps because of the novelty factor. ${ }^{7}$ A study has pointed out that in PPT the ability to integrate text, pictures, and images is a great advantage which improves the educative value of the subject. ${ }^{18}$ Some have argued that PPT presentations encourage an active learning environment, increase the effectiveness of lectures, and lend clarity to the subject. ${ }^{19-21}$

One disadvantage of PPT seems to be that the student becomes a passive observer rather than an active participant. ${ }^{22}$ It is suggested that although PPT has some positive effects, it does reduce the interactive discussion between teacher and students. ${ }^{23}$ In this study, one of the reasons the dental students preferred chalkboard teaching is that it gives better student-teacher interaction. In our interviews we noted students' opinions that the main reasons for liking lectures using chalkboard was that these contained natural pauses and breaks (eg, during writing or rubbing out the blackboard) allowing students to follow the material and take down their notes. In this context, a chalkboard may be said to be more student-centered while PPT is more teacher-centered. ${ }^{24}$ A chalkboard allows spontaneity and flexibility, and can be used with the lights on. Also it is not affected by broken glass (as in TOHP) or power loss (PPT and TOHP). ${ }^{5}$ This is important, especially in developing countries like India where factors such as limited infrastructure and an irregular power supply need to be taken into account (in contrast to the studies carried out in developed countries).

In their interviews the dental students said that they could take down diagrams and notes more easily with the chalkboard method. Regarding how this problem might be rectified when using PPT slides, it has been suggested that it is better to print out the PPT slides ${ }^{25}$ and give them to the students, or put them online, and/or to videotape the lecture and provide the videotape to the students.

With the lectures which used TOHP the main reason for liking this technique was that it is easier to take notes, provided the handwriting is legible. Of the presentations that were disliked, the main issues were poor visibility and that the presentation contained too much material and covered the material too quickly. It was explained in an article that although the use of a TOHP is easy and has some advantages, at times it can serve as a distraction. ${ }^{26}$

Some students commented that the effectiveness of the lecture depends upon the teacher, regardless of the teaching aid used, and in this context one study points out that what is fundamentally important in university teaching is not the quality of the technology but the quality of the teacher. ${ }^{27}$ A good teacher knows to start at a basic point of the course, which students can understand and then lead them gradually through the new and more difficult points. ${ }^{28}$

\section{Conclusion}

The medical students in our survey preferred the use of PPT presentations significantly over the other methods while the dental students did not prefer any particular method significantly. So students' preferences for a teaching method can vary greatly within the same institution given the same infrastructure and facilities.

Therefore, the present study, as well as the previous studies, does not bring out the superiority of any lecture 
delivery method. It appears that in the hands of a trained teacher any teaching aid would be appropriate and effective. This highlights the need for formal training in teaching technologies to develop good presentation skills and thus motivation of students.

\section{Disclosure}

The authors report no conflicts of interest in this work.

\section{References}

1. Brown G, Atkins M. Effective Teaching in Higher Education. London, UK: Routledge; 1988.

2. Cannon R. Lecturing, Kensington, NSW: Higher Education Research and Development Society of Australia; 1988.

3. Walton AJ. Lectures, Tutorials and the Like. Oxford and Lancaster, UK: MTP; 1972.

4. Sahu DR, Supe AN. The art and science of presentation: $35-\mathrm{mm}$ slides. J Postgrad Med. 2000;46:280-285.

5. Estes A, Ressler S, Welch R, Hanus J. Seminar on communication skills. Exceed teaching workshop 2009. Available from: http://www.asce.org/ uploadedFiles/Leadership_Training/EXCEED/USMA-09-Seminar-VIChalkboard.ppt. Accessed June 10, 2010.

6. Prasad S, Roy B, Smith M. The art and science of presentation: Electronic presentations. J Postgrad Med. 2000;46:193-198.

7. James KE, Burke LA, Hutchins HM. Powerful or pointless? Faculty versus student perceptions of PowerPoint in business education. Business Communication Quarterly. 2006;69:374-396.

8. Amare N. To slideware or not to slideware: Students' experiences with powerpoint vs lecture. Journal of Technical Writing and Communication. 2006;36:297-308.

9. Novelli ELB, Fernandes AAH. Students' preferred teaching techniques for biochemistry in biomedicine and medicine courses. Biochem Mol Biol Educ. 2007;35:263-266.

10. Savoy A, Proctor RW, Salvendy G. Information retention from PowerPoint and traditional lectures. Comput Educ. 2009;52:858-867.

11. Rocklin T. PowerPoint is not evil. In: The National Teaching and Learning Forum. New York, NY: Greenwood Publishing Group; 1998.

12. Bartsch RA, Cobern KM. Effectiveness of PowerPoint presentations in lectures. Computers and Education. 2003;41:77-86.

13. Szabo A, Hastings N. Using IT in the undergraduate classroom: should we replace the blackboard with PowerPoint? Comput Educ. 2000;35:175-187.

14. Lowry RB. Electronic presentation of lectures - effect upon student performance. U Chem Ed. 1999;8:18-21.
15. Ruffini MF. Creating Animations in PowerPoint to Support Student Learning and Engagement. EDUCAUSE Quarterly Magazine. 2009;32:4. Available from: http://www.educause.edu/EDUCAUSE+Quarterly/ EDUCAUSEQuarterlyMagazineVolum/CreatingAnimationsinPower Point/192966. Accessed June 10, 2010.

16. Harden RM. Death by PowerPoint-the need for a 'fidget index'. Med Teach. 2008;30:833-835.

17. Adibifar K. Students' perceptions of the use of technology: Does students' gender make a difference in their perceptions of using technology in teaching? Electronic Journal of Sociology. 2007. Available from: http://www.sociology.org/content/2007/adibifar_technology.pdf. Accessed June 10, 2010.

18. Mayer RE, Anderson RB. The instructive animation: Helping students build connections between words and pictures in multimedia learning. J Educ Psych. 1992;84:444-452.

19. Hunt N. Enhancing lectures the modern way. The New Academic. 1998:3-9.

20. Sammons MC. Using PowerPoint presentations in writing classes. The Technology Source. 1997. Available from: http://technologysource.org/ article/using_powerpoint_presentations_in_writing_classes. Accessed June 10, 2010.

21. Rossen S, McGraw D, Graham E, Lee D. "Enhancing your lecture with presentation software-Setting instructional goals". 1997 Last updated September 1997 by David McGraw for Faculty New Media Center (FNMC) at UCLA Office of Instructional Development. Available from: http://www.oid.ucla.edu Accessed June 10, 2010.

22. Casanova J, Casanova SL. Computers as electronic blackboard: Remodeling the organic chemistry lecture. Educom Re. 1991:31-34.

23. Garg A, Rataboli PV, Muchandi K. Students' opinion on the prevailing teaching methods in pharmacology and changes recommended. Indian J Pharmacol. 2004;36:155-158.

24. Creed T. PowerPoint No! Cyberspace Yes! In: The National Teaching and Learning Forum. New York, NY: Greenwood Publishing Group. 1998.

25. Adkins J. PowerSpeak: Forgotten fundamentals of presentation speaking. 2001. Available from: http://lowendmac.com/lab/01/0712. html. Accessed June 10, 2010.

26. Shah HK. Overhead Projector - A Versatile Teaching Tool. Indian J Community Med.2006;31. Available from: http://www.indmedica.com/ journals.php? journalid $=7$ andissueid $=73$ andarticleid $=942$ andaction $=$ article. Accessed June 10, 2010.

27. Ahmed C. PowerPoint versus traditional overheads. Which is more effective for learning? Paper presented at conference for the South Dakota Association for Health, Physical Education and Recreation. 1998.

28. Shallcross DE, Harrison TG. Lectures: electronic presentations versus chalk and talk - a chemist's view. Chem Educ Res Pract. 2007;8:73-79.
Advances in Medical Education and Practice

\section{Publish your work in this journal}

Advances in Medical Education and Practice is an international, peerreviewed, open access journal that aims to present and publish research on Medical Education covering medical, dental, nursing and allied healthcare professional education. The journal covers undergraduate education, postgraduate training and continuing medical education

\section{Dovepress}

including emerging trends and innovative models linking education, research, and healthcare services. The manuscript management system is completely online and includes a very quick and fair peer-review system. Visit http://www.dovepress.com/testimonials.php to read real quotes from published authors. 